\title{
Confirming the Diagnosis of Amyloidosis
}

\author{
Brendan Wisniowski Ashutosh Wechalekar
}

National Amyloidosis Centre, London, UK

\section{Keywords}

Amyloidosis $\cdot$ Amyloid $\cdot$ Diagnosis

\section{Abstract}

Amyloidosis is a general term for diseases characterised by the deposition of insoluble amyloid fibrils in organs or tissues, leading to organ dysfunction and, in many cases, death. Amyloid fibrils are derived from soluble precursor proteins, with the number of known amyloidogenic proteins increasing over time. The identity of the precursor protein often predicts the disease phenotype, although many of the amyloidoses have overlapping clinical features. Most patients with amyloidosis will require biopsy of an involved organ or tissue to confirm the diagnosis. Cardiac transthyretin amyloidosis, however, may be diagnosed without a biopsy provided stringent criteria are met. Where amyloid is confirmed histologically, the identity of the amyloidogenic protein must be determined, given several of the amyloidoses have diseasespecific therapies. Laser capture microdissection and tandem mass spectrometry, LCM-MS, has revolutionised amyloid subtyping, being able to identify the amyloidogenic protein more reliably than antibody-based methods such as immunohistochemistry. Here we summarise the biopsy approach to amyloidosis, as well as the non-biopsy diagnosis of cardiac transthyretin amyloidosis. Proteomic and antibody-based methods for amyloid subtyping are reviewed. Finally, an algorithm for confirming the diagnosis of amyloidosis is presented.

(c) 2020 S. Karger AG, Basel

\section{Introduction}

The diagnosis of amyloidosis can only be made histologically through the detection of amyloid deposits on tissue biopsy specimens, with the exception of cardiac transthyretin amyloidosis, which may be diagnosed without a tissue biopsy provided stringent criteria are met [1]. The protein forming the amyloid fibrils must then be identified to establish the type of amyloidosis. Typing is particularly important since a non-immunoglobulin light chain (non-AL) amyloidosis can occur with an unrelated plasma cell dyscrasia; misidentification may lead patients karger@karger.com www.karger.com/aha

(c) 2020 S. Karger AG, Basel

Karger"
Ashutosh Wechalekar

Centre for Amyloidosis and Acute Phase Proteins

Division of Medicine (Royal Free Campus), University College London

Rowland Hill Street, London NW3 2PF (UK)

a.wechalekar@ucl.ac.uk 

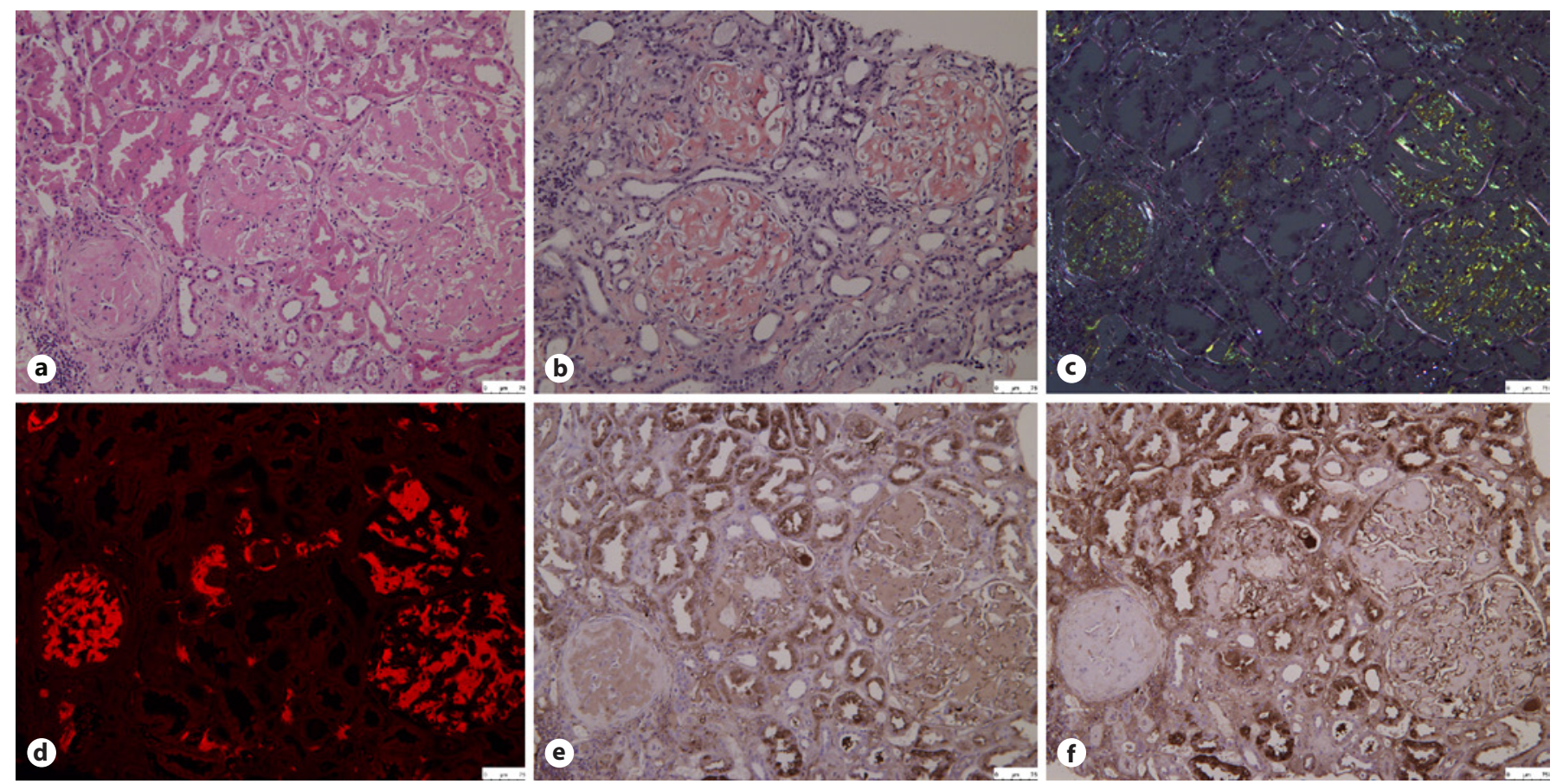

Fig. 1. Renal biopsy showing immunoglobulin light chain $(A L)$ amyloid, kappa type. a HE stain, $\times 100$. Note pink, amorphous material present within glomeruli. Similar material is also present in the interstitium. b Congo red, unpolarised light, $\times 100$. c Congo red, cross-polarised light, $\times 100$. Note the birefringence of amyloid giving an “apple-green" colour. d Congo Red, fluorescent light, $\times 100$. e IHC, anti-kappa, $\times 100$. Note moderate staining within glomeruli and interstitium; background staining is also present. $\mathbf{f}$ IHC, anti-lambda, $\times 100$. Note the absence of staining within glomeruli. Background staining is present.

to receive inappropriate chemotherapy on the presumption of AL amyloidosis if typing is not performed. This is crucial in cardiac transthyretin amyloidosis in the elderly (especially the African-American population), where the prevalence of an unrelated monoclonal gammopathy approaches $20 \%$ [1]. Immunohistochemistry (IHC) remains the most common method to characterise amyloid deposits, though may be inconclusive or misleading, particularly outside of centres of expertise [2]. Recently, mass spectrometry-based proteomic analysis of amyloid deposits has been shown to identify the amyloid subtype with a high degree of confidence [3,4], and is considered the gold standard.

The only type of amyloidosis that may be diagnosed without a tissue biopsy is cardiac transthyretin amyloidosis. In symptomatic patients with suggestive or characteristic findings of amyloidosis on echocardiogram and/or cardiac magnetic resonance imaging (MRI), a diagnosis of cardiac transthyretin amyloidosis may be established on the basis of scintigraphic imaging, provided no plasma cell dyscrasia is present [1].

Confirming the Diagnosis of Amyloidosis

\section{Diagnosis of Amyloidosis by Tissue Biopsy}

Amyloid deposits are visible on haematoxylin and eo$\sin (\mathrm{HE})$-stained histological sections as amorphous, eosinophilic deposits (Fig. 1a). HE staining is not specific for amyloid deposition since hyaline change or sclerosis give similar appearances [5].

Amyloid deposition is confirmed using thioflavin dyes, most commonly Congo red. On light microscopy, Congo red-stained amyloid deposits will appear red or salmon-pink (Fig. 1b). The confirmatory test is the appearance of characteristic birefringence under crosspolarised light when the amyloid deposits look applegreen, but may demonstrate other colours ranging from yellow-green or blue-green to apple green, partly as a consequence of additional birefringence introduced by other structures (e.g., glass slides) in the light path (Fig. 1c) [6]. Congo red may stain other structures (e.g., the elastic laminae of arteries, eosinophils, and myelomatous casts), although these will appear white under cross-polarised light. Meticulous attention to 


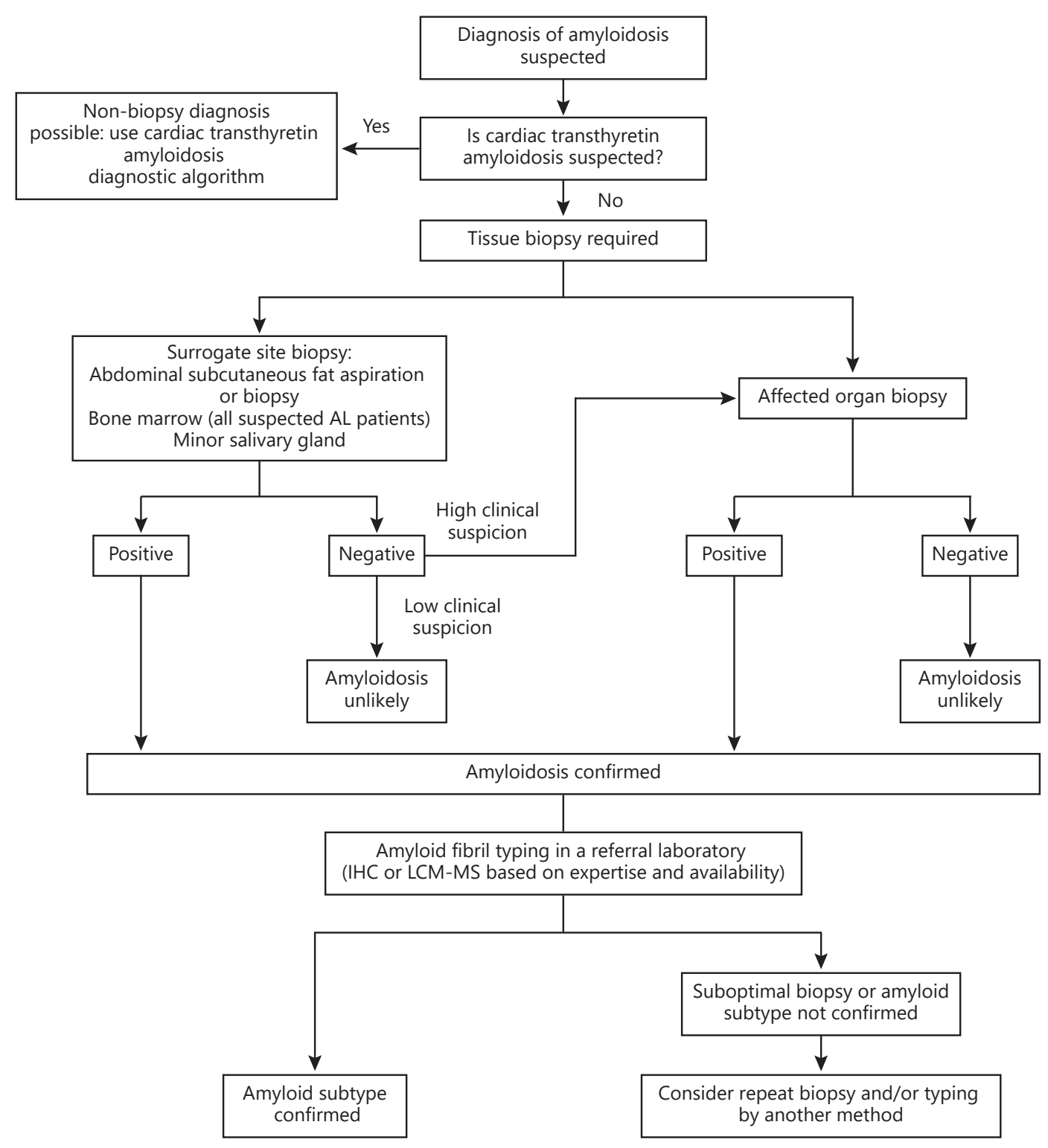

Fig. 2. Suggested algorithm for confirming the diagnosis of amyloidosis.

the staining technique is required, as overstaining may lead to false positive results and old stain may give false negative results. Amyloid deposits may be missed in thin sections and use of sections at least $5 \mu \mathrm{m}$ in thickness is recommended [6]. Novel fluorescent dyes show promise for both identifying and typing amyloid deposits $[7,8]$.

\section{Choosing the Biopsy Site}

Choosing the correct tissue or site to biopsy is crucial to avoid false negatives and delays to diagnosis. Localised amyloidoses can only be diagnosed by biopsy of the affected organ or tissue. Systemic amyloidoses, however, may also be diagnosed by biopsy of a surrogate site such 
as the abdominal fat, bone marrow, or minor salivary gland. The positive yield of such biopsies is dependent on both the surrogate site that is chosen and the type of amyloid deposits, with amyloid detection more likely in $\mathrm{AL}$ rather than transthyretin (ATTR) amyloidosis. Figure 2 presents a suggested algorithm for confirming the diagnosis of amyloidosis.

\section{Biopsy of a Clinically Involved Organ}

Biopsy of a clinically involved organ such as the kidney or heart is the most sensitive method to diagnose amyloidosis and has the advantages of allowing the detection of concomitant pathologies in addition to providing more tissue for subsequent amyloid typing [9]. Since amyloidosis may cause vascular fragility and a bleeding diathesis, the safety of organ biopsy in this setting has been questioned. However, in selected patients, the reported complication rates following organ biopsy are generally no higher among amyloidosis patients than controls. A review of complications of percutaneous renal biopsy from three teaching hospitals in the UK over a 25 -year period showed that the bleeding risk was no higher among amyloidosis patients than those with other pathologies [10]. Similar findings were reported in a study of 101 amyloidosis patients at the Mayo Clinic [11] as well as a more recent study of 88 patients with systemic AA amyloidosis [12]. In the largest study evaluating the safety of endomyocardial biopsy in cardiac amyloidosis, 4 complications occurred after 73 procedures, resulting in a complication rate of approximately $5.5 \%$ [13], which is similar to that reported for endomyocardial biopsy in general patient cohorts [14]. Liver biopsy has been associated with higher complication rates in amyloidosis [15], though data regarding the safety of techniques such as transjugular biopsy are not available.

\section{Biopsy of a Surrogate Site}

Although organ biopsy may be performed safely in selected patients with amyloidosis, it remains riskier than biopsy of a surrogate site, requires technical expertise to perform, and is associated with greater patient discomfort. For these reasons, biopsy of a surrogate site, which offers reasonable diagnostic sensitivity, is often recommended as the first-line diagnostic investigation, particularly for suspected AL amyloidosis $[9,16]$. Importantly, a negative biopsy at a surrogate site does not exclude amy-

Confirming the Diagnosis of Amyloidosis loidosis and should be followed by biopsy of an involved organ where the clinical suspicion remains high [17].

The choice of which surrogate site to biopsy is informed by local expertise, as well as the type of amyloidosis that is suspected. For example, patients suspected of having systemic AL amyloidosis should undergo bone marrow biopsy, which may not only confirm amyloid histologically, but also define the underlying plasma cell dyscrasia or lymphoproliferative disorder that is present.

\section{Abdominal Subcutaneous Fat Aspiration}

Abdominal subcutaneous fat aspiration (ASFA) is the most commonly used technique to diagnose amyloidosis at a surrogate site. It requires minimal technical expertise, causes little patient discomfort, and may be performed at the bedside. A description of the procedure is available online [18]. The main limitation of the technique is that it often provides limited tissue, which may result in false negative biopsies or inadequate amyloid for subsequent typing [19]. As such, use of a large-bore needle is recommended (e.g., $16 \mathrm{G}$ ) and aspiration should be performed at multiple sites on the abdominal wall if required [18]. The high diagnostic sensitivity for ASFA has often been reported by specialised amyloidosis centres $[20,21]$ and may be difficult to achieve in non-specialist settings [22]. As such, collaboration between the clinician and the pathology service is required before this technique is put into practice.

The technique was first evaluated in a 1973 study which reported abnormal aspirates in 9 out of 28 patients with suspected systemic AA amyloidosis [23]. Further studies have since been undertaken using patients with biopsy-proven amyloidosis, with good sensitivity reported for systemic amyloidosis of AL or AA type [20,21, 24, 25]. In 72 patients from the Mayo Clinic with systemic AL amyloidosis, the reported sensitivity of ASFA was $72 \%$ [20]. For patients with systemic AL amyloidosis with renal involvement, the sensitivity of ASFA has been reported to be higher (89.3\%) [25]. In a cohort of 120 patients attending a specialised amyloidosis centre in the Netherlands (70 with AL, 38 with AA, 12 with ATTR), the sensitivity of ASFA was $80 \%$ and increased to $93 \%$ when three smears were thoroughly examined by 2 observers [21].

Lately, studies have evaluated the use of ASFA in patients with suspected cardiac amyloidosis as a means of avoiding endomyocardial biopsy. ASFA has high sensitivity in cardiac AL amyloidosis, but is far less sensitive 
for hereditary cardiac transthyretin amyloidosis, and is still less sensitive for acquired cardiac transthyretin amyloidosis: in a large study of 600 patients in the UK, amyloid deposits were detected in 84,45 , and $15 \%$ of cases, respectively $[26,27]$. Similarly, in a cohort of patients with biopsy-proven cardiac transthyretin amyloidosis attending the Mayo Clinic, the sensitivity of ASFA for the diagnosis of hereditary and acquired disease was 67 and $14 \%$, respectively [27].

\section{Rectal Biopsy}

Whilst rectal biopsy, along with the abdominal subcutaneous fat, has been the surrogate site most often targeted to diagnose systemic amyloidosis, its usefulness has been supported by some [25, 28] but not all [29] studies. In a cohort of 20 patients with systemic AL amyloidosis from the Mayo Clinic, 17 had abnormal rectal biopsies, giving a sensitivity of $85 \%$ [30]. Amyloid deposition in the rectum most commonly occurs in the muscularis mucosae and submucosa and may be missed if the biopsy contains only mucosal tissue [30]. Rectal biopsy requires patient preparation, causes some patient discomfort, and significant complications such as bleeding and perforation, though very rare, may occur [31]. Importantly, in the setting of a negative ASFA, the yield of rectal biopsy has been reported to be low [21]. Hence, rectal biopsy is no longer routinely recommended as a first-line technique for amyloid diagnosis.

\section{Bone Marrow Biopsy}

Bone marrow biopsy is a routine part of the evaluation of patients with suspected systemic AL amyloidosis. The core biopsy is the preferred sample for the detection of amyloid deposits, though amyloid may occasionally be seen on the aspirate. In systemic AL amyloidosis, amyloid deposition is seen in only $50-60 \%$ of cases $[32,33]$. Amyloid deposits are limited to the blood vessels in about twothirds of cases [33]. When bone marrow biopsy is combined with ASFA, $90 \%$ of patients with systemic AL amyloidosis will have evidence of amyloid deposition in one or both samples, which has led some authors to recommend these investigations in combination as part of the routine diagnostic workup for this disease [34].

Amyloid deposits in the marrow should not be assumed to be of AL type, even if a plasma cell dyscrasia is present. In a cohort of patients with hereditary or ac- quired cardiac transthyretin amyloidosis, amyloid deposition in the marrow was seen in 41 and $30 \%$ of patients, respectively [27]. Similarly, amyloid deposition in the marrow is not uncommon in systemic AA amyloidosis, occurring in up to $80 \%$ of cases in small case series [35, 36].

\section{Biopsy of Other Surrogate Sites}

Minor salivary gland biopsy (MSLB) involves the removal of one or more minor salivary glands via a small incision in the labial mucosa adjacent to the mandibular canine tooth [37]. Transient complications such as paraesthesia and local swelling occur in approximately $10 \%$ of cases [38]. The procedure was first evaluated as a diagnostic tool for systemic amyloidosis in 1989. In a small cohort of 19 patients with suspected systemic AA amyloidosis from Peru, almost all of whom had antecedent tuberculosis, MSLB was positive in all cases, while being negative in all 11 controls [37]. In a French study of 30 patients with biopsy-proven systemic AA or AL amyloidosis, the sensitivity of MSLB was $86 \%$ [39]. Similarly high sensitivities for the diagnosis of systemic AL amyloidosis have been reported by more recent studies [40, 41]. MSLB has also been found to be useful for the histological confirmation of amyloid in familial amyloid polyneuropathy, with amyloid deposition seen in up to $91 \%$ of cases $[42,43]$.

Gingival biopsy has been used to diagnose amyloidosis [44], but is less sensitive and is associated with more patient discomfort than biopsy at other sites [45]. Biopsy of clinically uninvolved skin is also insensitive, being positive in approximately $50 \%$ of cases of systemic AA and AL amyloidosis [46].

\section{Characterisation of Amyloid Deposits}

Once amyloid deposits have been detected in histological sections, the amyloid subtype must be determined. While the type of amyloidosis may be suggested by the clinical presentation or the results of genetic testing, definitive diagnosis requires identification of the amyloid fibril protein [47]. Diagnostic accuracy is of the utmost importance, as the various amyloidoses have disease-specific treatments and differ greatly in their prognoses.

Various methods have been used to characterise amyloid deposits in histological sections, with antibody-based techniques such as IHC being the most common. More 
Fig. 3. Inconclusive amyloid typing by IHC. a Congo red, $\times 100$. Glomerular and interstitial amyloid is present. b Congo red, cross-polarised light, $\times 100$. "Apple-green" birefringence under cross-polarised light confirms positive staining as amyloid. c Anti-kappa IHC, $\times 100$. Glomerular amyloid deposits show positive staining. d Anti-lambda IHC, $\times 100$. Glomerular amyloid deposits show positive staining. Since the glomerular amyloid stains with both antikappa and anti-lambda antibodies, the result is inconclusive.
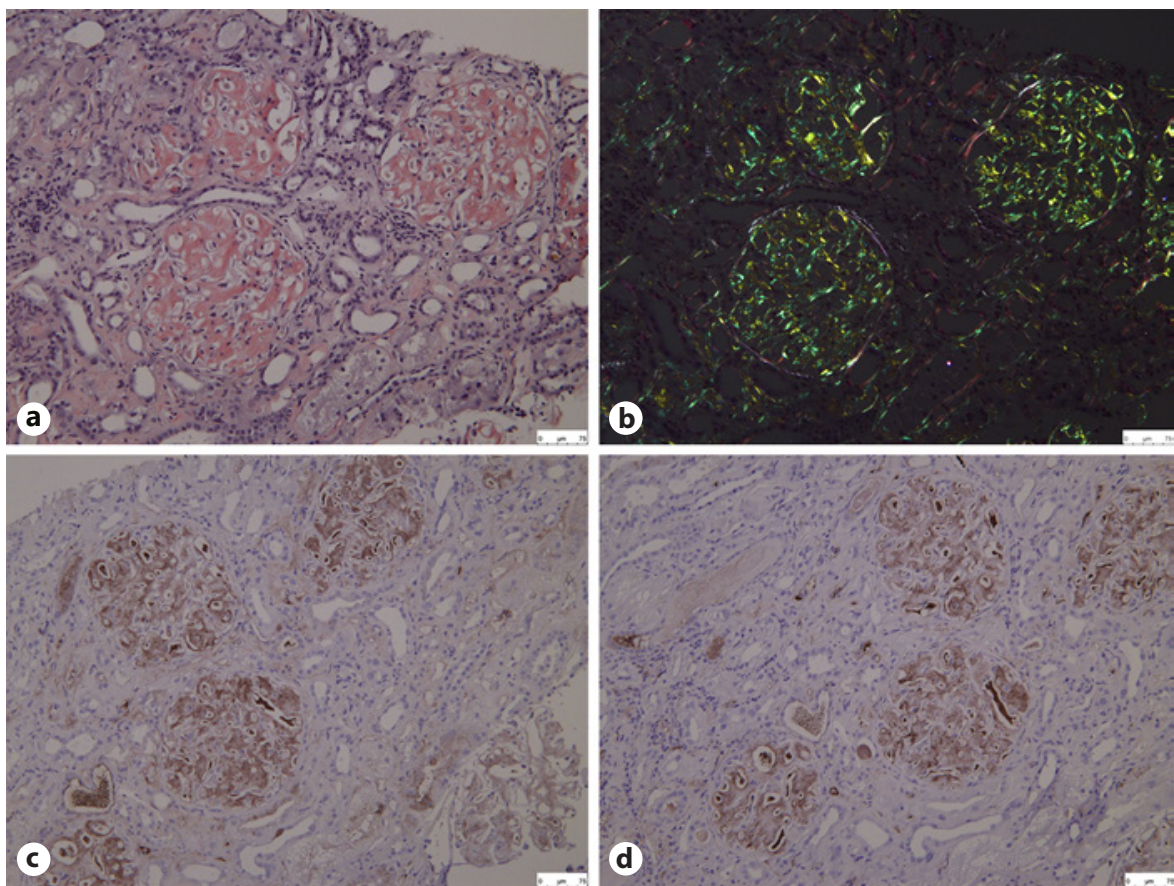

recently, mass spectrometry-based proteomic analysis has been shown to accurately characterise amyloid fibril proteins [3]. Modifications of the Congo red staining protocol, such as potassium permanganate pre-treatment (which abolishes the staining of AA amyloid with Congo red), were previously used for amyloid typing but are now considered obsolete [6].

\section{Immunohistochemistry}

IHC involves the use of antibodies against normal or aberrant protein epitopes within amyloid as a means of amyloid typing (Fig. 1e, f). It is inexpensive, widely available, and, in expert centres, can often characterise the amyloidogenic protein [48]. In a recent report of 142 biopsies reviewed at the National Amyloidosis Centre in the UK, IHC was diagnostic in 108 (76\%), and showed 100\% concordance with the results of laser capture microdissection and mass spectrometry (LCM-MS) performed on the same samples [48]. Similar success with IHC has been reported by other centres $[49,50]$, although in these studies the IHC results were verified only by correlation with ancillary clinical and laboratory data. Despite these findings, the performance of IHC is generally poor outside of specialised centres, owing to frequent inconclusive or misleading results (Fig. 3) [4, 51].

Confirming the Diagnosis of Amyloidosis
The pitfalls of IHC for amyloid typing are well recognised [52]. Without use of a validated panel of antibodies, the rate of false positives and negatives is unacceptably high. Background staining is common and may be due to non-immunological binding or the presence of normal proteins containing epitopes targeted by the antibody in the extracellular space [53]. The latter problem often complicates the identification of AL amyloid, as antibodies targeting kappa or lambda light chains may bind normal immunoglobulins in the specimen. Serum proteins may become trapped in amyloid deposits (a phenomenon known as contamination) [54], resulting in false positive results. Amyloidogenic proteins may lose some of their epitopes in the process of fibrillogenesis, resulting in poor or absent reactivity with commercial antibodies [55]. For example, AL amyloid may be derived from immunoglobulin light chain fragments predominantly containing the variable region, leading to false negative results when commercial antibodies targeting the constant region are used [2].

\section{Immunofluorescence and Immunoelectron Microscopy}

Immunofluorescence (IF) is similar to IHC, but uses antibodies labelled with fluorescent dyes against target epitopes, with the resultant staining pattern in tissue 
viewed using a fluorescence microscope (Fig. 1d). As autofluorescence may occur with paraffin sections, frozen sections are generally used. The use of frozen sections avoids problems that may be caused or exacerbated by fixation, such as the alteration of antigenic sites and the trapping of plasma proteins within tissue. As such, limited antibody reactivity and background staining have been reported to be less of an impediment to successful antibody typing when IF, as opposed to IHC, is used [56].

Similar to IHC, the use of IF for the characterisation of amyloid fibril proteins has been met with variable results $[57,58]$. A recent Mayo Clinic study has evaluated the performance of IF for amyloid typing, using the results of LCM-MS as a reference standard [59]. In this study, the sensitivity and specificity of IF for the diagnosis of immunoglobulin-derived (i.e., AL, AH, or both) amyloidosis was 84.6 and $92.4 \%$, respectively. Notably, 5 cases of systemic AA amyloidosis established by LCM-MS were diagnosed as immunoglobulin-derived amyloidosis by IF.

Immunoelectron microscopy (IEM) is a technique that combines IHC and electron microscopy. In this method, gold-labelled antibodies are used to characterise proteins within amyloid fibrils which have been identified by ultrastructural examination [60]. In a study of 423 cases of systemic amyloidosis diagnosed at a specialised amyloidosis centre in Italy, IEM was reported to identify the amyloid type in over $99 \%$ of cases [61]. However, the availability of IEM is limited, and a lack of expertise precludes wider use.

\section{Mass Spectrometry-Based Proteomic Typing}

Given the pitfalls associated with antibody-based methods for the characterisation of amyloid fibrils proteins, direct chemical characterisation of proteins within amyloid deposits is desirable. Laser capture microdissection of amyloid deposits followed by tandem mass spectrometry (LCM-MS) has emerged as a valuable tool for the identification of amyloid fibril proteins. LCM-MS has been described in detail elsewhere [62]. Briefly, amyloid deposits that have been identified on Congo red-stained formalin-fixed paraffin-embedded sections are dissected free with a laser capture microscope. The specimen is tryptically digested then subject to tandem mass spectrometry where the ionised peptides are dissociated into smaller fragments which are separated on the basis of their mass-to-charge ratios. Computer software is then used to analyse the resultant "fragmentation pattern" and compare it to reference protein databases for identifica-
Table 1. Scoring system for visual assessment of myocardial tracer uptake on bone scintigraphy in cardiac amyloidosis [66]

0. Absent cardiac uptake and normal bone uptake

1. Mild cardiac uptake, less than bone

2. Moderate cardiac uptake accompanied by attenuated bone uptake

3. Strong cardiac uptake with mild/absent bone uptake

tion of the native protein. Since amyloid deposits contain other constituent proteins in addition to the fibrillogenic protein, these will also be detected by LCM-MS. As these proteins (e.g., serum amyloid P) are present in all amyloid fibrils, they represent a "signature" to confirm the presence of amyloid.

In a landmark Mayo Clinic study, 50 diagnostic biopsy specimens from 50 patients with amyloidosis well characterised on clinicopathological grounds were evaluated with LCM-MS [3]. LCM-MS was reported to identify the amyloid subtype with $100 \%$ sensitivity and specificity. In a further set of 41 biopsies from patients with cardiac amyloidosis, LCM-MS was able to identify the amyloid subtype in $98 \%$ of cases, whereas IHC was informative in only $42 \%$. When both methods were informative, there was $100 \%$ concordance with LCM-MS and IHC.

The excellent performance of LCM-MS has been replicated by other studies. In a collaborative study undertaken by the National Amyloidosis Centre and the Mayo Clinic, accurate typing could be obtained using LCM-MS in $94 \%$ of cases, compared to $76 \%$ with IHC [48]. In a review of 131 biopsies received at an Australian amyloidosis referral centre, LCM-MS was able to identify an amyloidogenic protein in 121 cases (94\%), while in a subset of 87 cases in which IHC was attempted, it was informative in only 39 (45\%). LCM-MS has also been able to identify the amyloid subtype in cases where IEM is inconclusive [63].

\section{Non-Biopsy Diagnosis of Cardiac Transthyretin Amyloidosis}

Cardiac amyloidosis was first reported to demonstrate myocardial uptake on bone scintigraphy studies using radiolabelled phosphate derivatives in the late 1970s [64]. However, it was not until 2005 that the diagnostic utility of bone scintigraphy in cardiac amyloidosis was evaluated more formally. In an Italian study [65] of 25 patients with histologically confirmed cardiac amyloidosis (15 trans- 
thyretin related, $10 \mathrm{AL}$ ) and 10 controls, bone scintigraphy was performed using the ${ }^{99 \mathrm{~m}} \mathrm{Tc}$-3,3-diphosphono-1,2-propanodicarboxylic acid $\left({ }^{99 \mathrm{~m}} \mathrm{Tc}-\mathrm{DPD}\right)$ tracer, with visual assessment of myocardial uptake scored using a simple ordinal scale (Table 1). Myocardial uptake was present in all patients with cardiac transthyretin amyloidosis, but was absent in all cardiac AL amyloidosis patients as well as all controls.

These results inspired the development of an algorithm for the non-biopsy diagnosis of cardiac transthyretin amyloidosis, which was evaluated in a collaborative study involving 1,217 patients with suspected cardiac amyloidosis referred to specialised amyloid clinics in the USA and Europe [1]. In this study, the combined finding of grade 2 or 3 myocardial tracer uptake on bone scintigraphy and the absence of a monoclonal protein by serum and urine immunofixation electrophoresis and serum free light chain assay was $100 \%$ specific for cardiac transthyretin amyloidosis. Importantly, this study demonstrated that a minority of patients with cardiac AL amyloidosis, who will have evidence of a plasma cell dyscrasia in serum or urine in almost all cases [66], may also show moderate or marked myocardial tracer uptake on bone scintigraphy. As such, cardiac transthyretin amyloidosis cannot be diagnosed on non-biopsy criteria if a plasma cell dyscrasia is present, and tissue biopsy is still required in this situation.

\section{Conclusion}

With the exception of cardiac transthyretin amyloidosis, the diagnosis of amyloidosis can only be made histologically via the detection of amyloid on tissue biopsy. While biopsy of a clinically involved organ is associated with the highest diagnostic yield, biopsy of a surrogate site can also confirm the presence of amyloid, while being safer and more comfortable for the patient. The abdominal subcutaneous fat, bone marrow, and minor salivary gland are the surrogate sites most often used for amyloid detection.

Congo red staining should be used to confirm amyloid deposition. Newer methods are not yet widely available. Once amyloid is identified, subtyping must be performed to identify the amyloidogenic protein. This is of particular importance for patients with a plasma cell dyscrasia, who must not be presumed to have systemic AL amyloidosis. Typing of amyloid deposits should be undertaken only in specialist referral laboratories due to the grave consequences of misdiagnosis. Antibody-based methods such as IHC or IEM are reasonable first-line investigations for amyloid typing in experienced laboratories. Where the amyloid subtype is not confirmed using antibody-based methods, laser capture followed by tandem mass spectrometry should be used as the method of choice for confirmation of amyloid fibril type.

\section{Disclosure Statement}

The authors have no conflicts of interest to declare.

\section{Funding Sources}

Not applicable.

\section{Author Contributions}

Brendan Wisniowski and Ashutosh Wechalekar wrote and revised the paper, and approved it for final submission.

\section{References}

1 Gillmore JD, Maurer MS, Falk RH, Merlini G, Damy T, Dispenzieri A, et al. Nonbiopsy diagnosis of cardiac transthyretin amyloidosis. Circulation. 2016 Jun;133(24):240412.

2 Picken MM, Herrera GA. The burden of "sticky" amyloid: typing challenges. Arch Pathol Lab Med. 2007 Jun;131(6):850-1.

3 Vrana JA, Gamez JD, Madden BJ, Theis JD, Bergen HR 3rd, Dogan A. Classification of amyloidosis by laser microdissection and mass spectrometry-based proteomic analysis in clinical biopsy specimens. Blood. 2009 Dec; 114(24):4957-9.

Confirming the Diagnosis of Amyloidosis
4 Mollee P, Boros S, Loo D, Ruelcke JE, Lakis VA, Cao KL, et al. Implementation and evaluation of amyloidosis subtyping by laser-capture microdissection and tandem mass spectrometry. Clin Proteomics. 2016 Oct;13(1):30.

5 Doganavsargil B, Buberal GE, Toz H, Sarsik B, Pehlivanoglu B, Sezak M, et al. Digitally reinforced hematoxylin-eosin polarization technique in diagnosis of rectal amyloidosis. World J Gastroenterol. 2015 Feb;21(6):1827-37.

6 Howie AJ. Diagnosis of amyloid using Congo red. In: Picken MM, Herrera GA, Dogan A, editors. Amyloid and Related Disorders. Berlin: Springer; 2012. pp. 167-73.
7 Nilsson KP, Ikenberg K, Aslund A, Fransson S, Konradsson P, Röcken C, et al. Structural typing of systemic amyloidoses by luminescent-conjugated polymer spectroscopy. Am J Pathol. 2010 Feb;176(2):563-74.

8 Sipe JD, Benson MD, Buxbaum JN, Ikeda S, Merlini G, Saraiva MJ, et al.; Nomenclature Committee of the International Society of Amyloidosis. Amyloid fibril protein nomenclature: 2012 recommendations from the Nomenclature Committee of the International Society of Amyloidosis. Amyloid. 2012 Dec; 19(4):167-70. 
9 Mollee P, Renaut P, Gottlieb D, Goodman H. How to diagnose amyloidosis. Intern Med J. 2014 Jan;44(1):7-17.

10 Hutchison CA, Pinney JH, Jain P, Cockwell P. Renal biopsies are safe in patients with multiple myeloma and amyloidosis. ASN Renal Week. 2009:SA-PO2343.

11 Soares SM, Fervenza FC, Lager DJ, Gertz MA, Cosio FG, Leung N. Bleeding complications after transcutaneous kidney biopsy in patients with systemic amyloidosis: single-center experience in 101 patients. Am J Kidney Dis. 2008 Dec;52(6):1079-83.

12 Altindal M, Yildirim T, Turkmen E, Unal M, Boga I, Yilmaz R, et al. Safety of percutaneous ultrasound-guided kidney biopsy in patients with AA amyloidosis. Nephron. 2015;131(1): $17-22$.

13 Falk RH, Kruger JL, Winters GL, Mitchell RN, Padera RF. Safety and value of endomyocardial biopsy in cardiac amyloidosis. Amyloid. 2010;17(suppl 1):153.

14 From AM, Maleszewski JJ, Rihal CS. Current status of endomyocardial biopsy. Mayo Clin Proc. 2011 Nov;86(11):1095-102.

15 Luk GD. The safety of needle liver biopsy in amyloidosis. Gastroenterology. 1978;75(5):975.

16 Gertz MA. Immunoglobulin light chain amyloidosis: 2014 update on diagnosis, prognosis, and treatment. Am J Hematol. 2014 Dec; 89(12):1132-40.

17 Gillmore JD, Wechalekar A, Bird J, Cavenagh J, Hawkins S, Kazmi M, et al.; BCSH Committee. Guidelines on the diagnosis and investigation of AL amyloidosis. Br J Haematol. 2015 Jan;168(2):207-18.

18 Hazenberg B. Fat aspiration procedure for the detection of amyloid [Internet]. 2011 [cited 17/02/2020]. Available from: http://www.amyloid.nl/Files/Fat\%20aspiration\%20procedure02.pdf.

19 Gilbertson JA, Botcher NA, Rowczenio D, Whelan CJ, Lachmann HJ, Wechaleckar A, et al. Diagnostic value of fat aspirates for amyloidosis in 950 patients. Orphanet J Rare Dis. 2015;10(suppl 1):50.

20 Gertz MA, Li CY, Shirahama T, Kyle RA. Utility of subcutaneous fat aspiration for the diagnosis of systemic amyloidosis (immunoglobulin light chain). Arch Intern Med. 1988 Apr; 148(4):929-33.

21 van Gameren II, Hazenberg BP, Bijzet J, van Rijswijk MH. Diagnostic accuracy of subcutaneous abdominal fat tissue aspiration for detecting systemic amyloidosis and its utility in clinical practice. Arthritis Rheum. 2006 Jun; 54(6):2015-21.

22 Halloush RA, Lavrovskaya E, Mody DR, Lager D, Truong L. Diagnosis and typing of systemic amyloidosis: the role of abdominal fat pad fine needle aspiration biopsy. Cytojournal. 2010 Jan;6(24):24.

23 Westermark P, Stenkvist B. A new method for the diagnosis of systemic amyloidosis. Arch Intern Med. 1973 Oct;132(4):522-3.

24 Klemi PJ, Sorsa S, Happonen RP. Fine-needle aspiration biopsy from subcutaneous fat. An easy way to diagnose secondary amyloidosis. Scand J Rheumatol. 1987;16(6):429-31.

25 Li T, Huang X, Cheng S, Zhao L, Ren G, Chen $\mathrm{W}$, et al. Utility of abdominal skin plus subcutaneous fat and rectal mucosal biopsy in the diagnosis of $\mathrm{AL}$ amyloidosis with renal involvement. PLoS One. 2017 Sep;12(9): e0185078.

26 Quarta CC, Gonzalez-Lopez E, Gilbertson JA, Botcher N, Rowczenio D, Petrie A, et al. Diagnostic sensitivity of abdominal fat aspiration in cardiac amyloidosis. Eur Heart J. 2017 Jun;38(24):1905-8.

27 Fine NM, Arruda-Olson AM, Dispenzieri A, Zeldenrust SR, Gertz MA, Kyle RA, et al. Yield of noncardiac biopsy for the diagnosis of transthyretin cardiac amyloidosis. Am J Cardiol. 2014 May;113(10):1723-7.

28 Hazenberg BP, Van Rijswijk MH, Meijer S, Marrink J, Limburg PC, Janssen S. Systemic amyloidosis: a clinical survey of 162 cases. In: Isobe T, editor. Amyloid and amyloidosis. Berlin: Springer; 1988.

29 Poulopoulos A, Sotsiou F, Vosnides G, Nikolopoulou N, Marinos L, Margellos B, et al. Comparative evaluation of rectal and renal biopsy in the diagnosis of systemic amyloidosis. Kidney Int. 1991;39:186.

30 Kyle RA, Spencer RJ, Dahlin DC. Value of rectal biopsy in the diagnosis of primary systemic amyloidosis. Am J Med Sci. 1966 May; 251(5):501-6.

31 Mulholland MW, Doherty GM. Complications in surgery. Philadelphia: Lippincott Williams \& Wilkins; 2005. p. 735.

32 Kyle RA, Gertz MA. Primary systemic amyloidosis: clinical and laboratory features in 474 cases. Semin Hematol. 1995 Jan;32(1):45-59.

33 Swan N, Skinner M, O'Hara CJ. Bone marrow core biopsy specimens in AL (primary) amyloidosis. A morphologic and immunohistochemical study of 100 cases. Am J Clin Pathol. 2003 Oct;120(4):610-6.

34 Gertz MA, Lacy MQ, Dispenzieri A. Amyloidosis: recognition, confirmation, prognosis, and therapy. Mayo Clin Proc. 1999 May; 74(5):490-4.

35 Sungur C, Sungur A, Ruacan S, Arik N, Yasavul U, Turgan C, et al. Diagnostic value of bone marrow biopsy in patients with renal disease secondary to familial Mediterranean fever. Kidney Int. 1993 Oct;44(4):834-6.

36 Sungur C, Sungur A, Akpolat T, Arik N. Diagnostic value of bone marrow biopsy in patients with AA-type renal amyloidosis secondary to ankylosing spondylitis. Nephrol Dial Transplant. 1996 Dec;11(12):2520-1.

37 Delgado WA, Mosqueda A. A highly sensitive method for diagnosis of secondary amyloidosis by labial salivary gland biopsy. J Oral Pathol Med. 1989 May;18(5):310-4.

38 Caporali R, Bonacci E, Epis O, Bobbio-Pallavicini F, Morbini P, Montecucco C. Safety and usefulness of minor salivary gland biopsy: retrospective analysis of 502 procedures performed at a single center. Arthritis Rheum. 2008 May;59(5):714-20.
39 Hachulla E, Janin A, Flipo RM, Saïle R, Facon $\mathrm{T}$, Bataille $\mathrm{D}$, et al. Labial salivary gland biopsy is a reliable test for the diagnosis of primary and secondary amyloidosis. A prospective clinical and immunohistologic study in 59 patients. Arthritis Rheum. 1993 May; 36(5):691-7.

40 La Verde G, Bianchi MP, Antolino G, Galassi G, Festuccia F, Bandiera G, et al. Diagnostic value of minor salivary glands biopsy in systemic amyloidosis. Blood. 2015;126(23):5381.

41 Suzuki T, Kusumoto S, Yamashita T, Masuda A, Kinoshita S, Yoshida T, et al. Labial salivary gland biopsy for diagnosing immunoglobulin light chain amyloidosis: a retrospective analysis. Ann Hematol. 2016 Jan;95(2):279-85.

42 Lechapt-Zalcman E, Authier FJ, Creange A, Voisin MC, Gherardi RK. Labial salivary gland biopsy for diagnosis of amyloid polyneuropathy. Muscle Nerve. 1999 Jan;22(1): 105-7.

43 Do Amaral B, Coelho T, Sousa A, Guimarães A. Usefulness of labial salivary gland biopsy in familial amyloid polyneuropathy Portuguese type. Amyloid. 2009 Dec;16(4):232-8.

44 Selikoff IJ, Robitzek EH. Gingival biopsy for the diagnosis of generlized amyloidosis. Am J Pathol. 1947 Nov;23(6):1099-111.

45 Gafni J, Sohar E. Rectal biopsy for the diagnosis of amyloidosis. Am J Med Sci. 1960 Sep; 240:332-6.

46 Rubinow A, Cohen AS. Skin involvement in generalized amyloidosis. A study of clinically involved and uninvolved skin in 50 patients with primary and secondary amyloidosis. Ann Intern Med. 1978 Jun;88(6):781-5.

47 Picken MM, Westermark P. Amyloid detection and typing: summary of current practice and recommendations of the consensus group. Amyloid. 2011 Jun;18 Suppl 1:48-50.

48 Gilbertson JA, Theis JD, Vrana JA, Lachmann $\mathrm{H}$, Wechalekar A, Whelan C, et al. A comparison of immunohistochemistry and mass spectrometry for determining the amyloid fibril protein from formalin-fixed biopsy tissue. J Clin Pathol. 2015 Apr;68(4): $314-7$.

49 De Larrea CF, Sole M, Cibeira MT, Tovar N, Rosinol L, Elena M, et al. Role of immunohistochemistry in the diagnosis of systemic immunoglobulin light-chain amyloidosis: results in a series from a single institution. Haematologica. 2014;99 S1:376.

50 Schönland SO, Hegenbart U, Bochtler T, Mangatter A, Hansberg M, Ho AD, et al. Immunohistochemistry in the classification of systemic forms of amyloidosis: a systematic investigation of 117 patients. Blood. 2012 Jan; 119(2):488-93.

51 Latalova P, Holub D, Pika T, Flodr P, Majduch $M$. Amyloid typing using immunohistochemical and proteomic analysis. Virchows Arch. 2015;467 S1:197.

52 Solomon A, Murphy CL, Westermark P. Unreliability of immunohistochemistry for typing amyloid deposits. Arch Pathol Lab Med. 2008 Jan;132(1):14. 
53 Linke RP. Routine use of amyloid typing on formalin-fixed paraffin sections from $626 \mathrm{pa}$ tients by immunohistochemistry. In: Picken MM, Herrera GA, Dogan A, editors. Amyloid and reated disorders. Berlin: Springer; 2012. pp. 219-29.

54 Kebbel A, Röcken C. Immunohistochemical classification of amyloid in surgical pathology revisited. Am J Surg Pathol. 2006 Jun;30(6): 673-83.

55 Gilbertson JA, Hunt T, Hawkins PN. Amyloid typing: experience from a large referral centre. In: Picken MM, Herrera GA, Dogan A, editors. Amyloid and related disorders. Berlin: Springer; 2012. pp. 231-8.

56 Picken MM. Options for amyloid typing in renal pathology: the advantages of frozen section immunofluorescence and a summary of general recommendations for immunohistochemistry. In: Picken MM, Herrera GA, Dogan A, editors. Amyloid and related disorders. Berlin: Springer; 2012. pp. 239-48.
57 Collins AB, Smith RN, Stone JR. Classification of amyloid deposits in diagnostic cardiac specimens by immunofluorescence. Cardiovasc Pathol. 2009 Jul-Aug;18(4):205-16.

58 Novak L, Cook WJ, Herrera GA, Sanders PW. $\mathrm{AL}$-amyloidosis is underdiagnosed in renal biopsies. Nephrol Dial Transplant. 2004 Dec; 19(12):3050-3.

59 Gonzalez Suarez ML, Zhang P, Nasr SH, Sathick IJ, Kittanamongkolchai W, Kurtin PJ, et al. The sensitivity and specificity of the routine kidney biopsy immunofluorescence panel are inferior to diagnosing renal immunoglobulin-derived amyloidosis by mass spectrometry. Kidney Int. 2019 Oct;96(4):1005-9.

60 Verga L, Morbini P, Palladini G, Obici L, Necchi V, Paulli M, et al. Amyloid typing: immunoelectron microscopy. In: Picken MM, Herrera GA, Dogan A, editors. Amyloid and related disorders. Berlin: Springer; 2012.

61 Fernández de Larrea C, Verga L, Morbini P, Klersy C, Lavatelli F, Foli A, et al. A practical approach to the diagnosis of systemic amyloidoses. Blood. 2015 Apr;125(14):2239-44.
62 Picken MM. Proteomics and mass spectrometry in the diagnosis of renal amyloidosis. Clin Kidney J. 2015 Dec;8(6):665-72.

63 Lavatelli F, Valentini V, Palladini G, Verga L, Russo P, Foli A, et al. Mass spectrometry-based proteomics as a diagnostic tool when immunoelectron microscopy fails in typing amyloid deposits. Amyloid. 2011 Jun;18(Suppl 1):64-6.

64 Kula RW, Engel WK, Line BR. Scanning for soft-tissue amyloid. Lancet. 1977 Jan;1(8002): 92-3.

65 Perugini E, Guidalotti PL, Salvi F, Cooke RM, Pettinato C, Riva L, et al. Noninvasive etiologic diagnosis of cardiac amyloidosis using 99mTc-3,3-diphosphono-1,2-propanodicarboxylic acid scintigraphy. J Am Coll Cardiol. 2005 Sep;46(6):1076-84.

66 Palladini G, Russo P, Bosoni T, Verga L, Sarais $\mathrm{G}$, Lavatelli $\mathrm{F}$, et al. Identification of amyloidogenic light chains requires the combination of serum-free light chain assay with immunofixation of serum and urine. Clin Chem. 2009 Mar;55(3):499-504. 